October - 2002

\title{
Using Web-Based, Group Communication Systems to Support Case Study Learning at a Distance
}

\author{
Liam Rourke \\ University of Alberta \\ Canada \\ Terry Anderson \\ Athabasca University \\ Canada
}

\begin{abstract}
This study explored the capacity of Web-based, group communication systems to support case-based teaching and learning. Eleven graduate students studying at a distance were divided into three groups to collaborate on a case study using either a synchronous voice, an asynchronous voice, or a synchronous text communication system. Participants kept a detailed log of the time they spent on various activities, wrote a 1,500-word reflection on their experience, and participated in a group interview. Analysis of these data reveals that each group supplemented the system that had been assigned to them with additional communication systems in order to complete the project. Each of these systems were used strategically: email was used to share files and arrange meetings, and synchronous voice systems were used to brainstorm and make decisions. Learning achievement was high across groups and students enjoyed collaborating with others on a concrete task. Keywords: Distance Education, Case-based Learning, Collaboration Software, Online Learning.

The evidence in favour of case-based teaching and learning continues to mount (cf. Lundeberg, Levin, and Harrington, 1999). One interesting facet of this research suggests that group discussions are the active ingredient of case study learning. For on-campus students this is simple to arrange, but where does it leave students who are studying at a distance? Case studies are often used in distance education, but traditionally they have been implemented in an independent mode, with students reading a problem-centred or exemplary narrative in order to contemplate its central issues. This type of case-based teaching omits what may be the most important part of case-based pedagogy.

Fortunately, a wide array of Web-based communication software exists that supports various types of communication at a distance, including text or voice, person-to-person or multi-person, and synchronous or asynchronous interaction. The relative effectiveness of these systems to support collaboration among students is an important issue to distance educators.
\end{abstract}


Rourke \& Anderson - Using Web-Based, Group Communication Systems to Support Case Study Learning at a Distance

\section{Literature Review}

\section{Case-based Teaching and Learning}

The Educational Resources Information Centre (ERIC) (2002) describes case-based teaching as "the practice of using real or imagined scenarios, critical incident analyses, case studies, vignettes, or anecdotal accounts as pedagogical tools in fields such as law, business, medicine, and education.” Carter (1999) distinguishes between two types of cases. An exemplar is a brief episode that clearly epitomizes a concept or issue. These episodes illustrate a general category or exemplify a practice. Their purpose is to increase clarity, make information more interesting, and concretize and contextualize information. Problem-situations are problem-centered stories of practice that are used to examine and clarify the complexities of practice. The purpose of problem situations is to provide students with opportunities for interpretation, analysis, inquiry, and problem solving.

Research on case-based teaching and learning indicates that it may be used to achieve several goals. Lundeberg (1999) identifies four outcomes, the first of which is the development of connections between theoretical and practical knowledge. By comparing students' solutions to a case at the beginning and at the end of a semester, and by analyzing students' explanations of the transformations, Lundeberg and Fawver (1993) found significant changes in their ability to connect theoretical principles to situated problems.

Lundeberg (1999) identified reasoning and reflective decision-making as the second outcome. Problem-based cases, especially those that admit several equally valid solutions, help students to understand the tentativeness in knowing, in turn providing them with opportunities to marshal and evaluate evidence for judging alternative interpretations and actions. Harrington (1995) found that although many students were able to identify the problem in a case, most benefited from practice in using facts and issues from the case, allowing them to ground their identification of the problem or to justify their solution.

Lundeberg identifies meta-cognition — being aware and evaluative of how one thinks as the third outcome. Bartlett and Sather (1992) demonstrated that when students analyze cases, especially if they do so multiple times, they become aware of the assumptions, strategies, and cognitive processes that characterize their interpretations of events.

Lundeberg (1999) identified epistemological growth as a final outcome. Epistemology is the discussion of what counts as knowledge, as truth, and how these claims are justified. Barnet and Tyson (1999) found that the discussions by students focused on case studies "affect their views regarding the sources of knowledge. They shift from thinking that knowledge stems from external sources to thinking that knowledge can be gained from internal sources and peers” (p. 17).

\section{Learning through Discussion}

Several researchers argue that the key element in achieving each of these outcomes is the discussions that the cases stimulate. Shulman (1999), for instance, notes: "Discussion during case method sessions is an essential part of the meaning making process. The focus is not simply on the cases themselves, but also on group deliberation about cases to stimulate analysis, decision-making, and reflection” (p. 16). 
Research on learning through discussion shows that it can be effective in facilitating higher order learning; however, what actually happens as students interact in small groups seems to vary widely in terms of quality and quantity of discourse. Some researchers who have analyzed transcripts of educational small group interactions have characterized the process as "series of superficially-related monologues" (Rourke, Anderson, Garrison, and Archer, 1999) or "mindless and unreflective bull sessions" (Roby, 1988). Others have found evidence of increasing amounts of deep learning as discussion continues on a case (Arnitt, Slack, Green, and Beer, 2002). In best examples of educational discussion, students offer their interpretations which are supported by evidence, and challenge the opinions of others; in short, they engage in the types of processes that actually make discussion a valuable learning activity.

\section{Case-based Learning in Distance Education}

Recently, distance education instructors have become interested in whether case studies can be used in their courses. Borsa, Klotz, and Uzat (1998), for instance, connected graduate students from two universities via a listserv, and had them work collaboratively on a problem-situation type of case study. Aside from the customary educational objectives of their respective courses, namely synthesis and evaluation, these instructors wanted to give their students an opportunity to develop collaborative problem-solving skills. The authors concluded that the achievement of these objectives is dependent upon the instructors' and the students' facility with the technology, and with an appropriate implementation of case-based teaching principles. Cheney (2000) added a set of four cases to her distance learning course on special education and encouraged students to discuss the problem-situations with each other via a computer-based bulletin board. A survey distributed to each of the 56 students shows that they enjoyed reading other students' interpretations of the cases and comparing them with their own. Students also valued the input from professionals whom Cheney invited to participate periodically in the discussions. Comparing her face-to-face and distance teaching experiences, Cheney noted that the case method worked equally well in both situations; in fact, she reported that the lack of restrictions of time and place on the bulletin board prompted more diversity in the discussions.

The literature on the case method of teaching and learning in distance education contexts is meager. Perhaps this is because it has been complicated, expensive, and demanding to support case-based teaching and learning among students who are studying at a distance. However, the increasing availability of several types of Web-based, group communication software may overcome these problems. From the early and simple asynchronous, point-to-point, text systems such as email, to the latest synchronous, multipoint, multimedia systems, distance educators have a variety of communications tools from which to choose.

\section{Media Comparison}

What criteria should inform these choices? According to Clark (1994), media should never influence learning; therefore, any available, inexpensive, functional communication system should do. Yet, it seems unlikely that email would be as effective as, say, videoconferencing in supporting students' case study deliberations.

Media theorists argue that there are important differences. Communication researchers, such as Short, Williams, and Christie (1976) studying these phenomena in the 1970s, noted that interpersonal communication is a complex process, which, to be effective, 
relies on a host of signals, both verbal and nonverbal. They concluded that the ultimate communicative experience occurs face-to-face, and is devalued as one loses signals or channels: a face-to-face meeting is better than a telephone conversation, which in turn is more effective than a faxed memo. In the subsequent decade, Daft and Lengel (1984) presented an articulated version of this argument and suggested that media are differentially suited to specific tasks. For instance, face-to-face communication is beneficial for rhetorical and persuasive tasks, but is too rich and therefore distracting and inefficient for simple information transmission tasks. Sometimes when we call a person, we are hoping to get their answering machine.

\section{Purpose}

The purpose of this study is to explore the capacity of three Web-based, group collaboration systems to support case-based teaching and learning with students who are studying at a distance. The intent is to investigate whether unique features of the systems have any influence on the time that groups spend on the activity, the activities they engage in, and the satisfaction and learning achievement that ensue.

\section{Method}

This study can broadly be described as an action research project in that the primary researcher was investigating learning activity in his own class. Kemmis and McTaggart (1988) define action research as "a form of collective self-reflective inquiry undertaken by participants in a social situation in order to improve the rationality and justice of their own social practices, as well as their understanding of these practices and the situations in which these practices are carried out” (p. 5).

Students were recruited from an optional, advanced instructional technology course that was delivered to Masters of Distance Education students at a major open learning university. This program contained no face-to-face components; although none of the students engaged in our project had met each other face-to-face, many had participated in earlier courses. Of the 30 students enrolled in the course, 11 volunteered to participate in this research project, and the activity counted as a major component of their assessment in the course.

The 11 students were randomly assigned to three separate groups, each of which used one of three Web-based, group communication technologies to complete the case study: Wimba, an asynchronous voice system; MSN Messenger, a synchronous text system; and Tutor'sEdge, a synchronous voice system.

\section{The Case}

The instructor authored the case that the students analyzed. It was brief (134-words), and fits Carter's (1999) description of a problem situation. The case read:

The Board of SaveMore College has just developed a strategic plan calling for an increase of 50 per cent in enrolment using distance education technologies. The Faculty Association has threatened to strike if this new policy has any adverse effect on faculty workloads. The Vice President has asked your team to prepare a 3,000-word report for both the Board and the Association that alleviates the Faculty concerns and provides a set of Action Recommendations that allows implementation of the new strategic plan. The report should recommend a technology platform and an implementation plan, and it 
should also discuss the effect of your recommendations on the college budget. You may model SaveMore College on TechBC (http://www.techbc.ca) in terms of student numbers, budget etc., but feel free to devise fictional, but plausible plans in line with the fictional nature of SaveMore College.

The groups were directed to prepare a 3,000-word report to the 'Board' in 15-days, and to present and defend their recommendations to the 'Board' during a 30-minute audioteleconference presentation. The 'Board' consisted of the course instructor, one of his colleagues, and the first author.

\section{Data Collection}

In addition to the written and verbal reports, three sources of data were used in this study. Students were asked to maintain an activity-time log, write a reflection on the project, and participate in a group interview. Each of these sources of data is described in detail below.

In order to keep track of how much time each of the groups spent on the case study and what types of activities they were engaged in, they were asked to keep a log. Each participant received a table which, for each of the days of the case study, included a cell for activity, time, and number of emails exchanged with group members. Students were also provided with a closed set of numbered activities from which to choose. The set was adapted from Hunter's (1997) list of processes for case study group work. It included seven activities:

1. Learning/experimenting with the technology

2. Planning group work

3. Identifying and evaluating the problem

4. Working towards a solution individually

5. Working toward a solution collaboratively

6. Preparing the final product individually

7. Preparing the final product collaboratively

An additional purpose of the list was to provide students with guidelines for successful collaboration. Therefore, they were sent Hunter's unabridged version of the list. Activity two, for example, "planning group work," included the following description:

"Discussing what the case requires of the group, identifying any individual strengths of group members that apply to the case, deciding on the steps that will be taken and the amount of time that will be allotted to each one, and assigning group roles."

We also asked students to reflect on their experience by writing a 1,500-word essay. We encouraged them to consider issues such as how the communication technology influenced group communication, scheduling, efficiency of completing the assignment, individual learning, group problem solving processes, and critical thinking.

Once the students had completed the assignment and we had reviewed their logs and reflections, we arranged a group interview. The purpose of this interview was to explore the themes students had introduced in the reflections and logs and to test some of the conclusions we were drawing. The interview, which lasted one hour, was conducted via audio-conference. 


\title{
Results
}

The most powerful piece of evidence, and one of the most important for interpreting the data, is that none of the groups maintained the fidelity of their treatment. Each of the groups actively sought and used communication technologies other than the one they had been issued in order to complete the assignment. The synchronous voice and synchronous text groups relied heavily on asynchronous technologies such as email to complete the project, and the asynchronous voice group abandoned their technology altogether after the first week.

The students' reflections indicate that each of the assigned and contraband communication technologies was used strategically. Across groups, email was used for exchanging files and scheduling meetings. Synchronous voice tools were used for brainstorming, discussing, and decision-making. Learning management systems (LMS) were used for document management. One student described the process for us:

"[The synchronous text tool] was used to work collaboratively in real time on items that needed group consensus, to offer opinions, and to make suggestions for further elaboration. Email was used to exchange work, verify minor details between [synchronous text] sessions, and to help set up meeting times" (synchronous text group member).

Similar explanations were offered by members of the other two groups, including this one in which a student describes the optimal use of email, an LMS, and a synchronous voice tool:

\begin{abstract}
"Asynchronous communication is great for planning synchronous meeting times, passing along URLs and content ideas, and sharing files. Having [an LMS] - a visual site to post work-in-progress that everyone can access - allows people to see who is doing what, and how things are organized. When we found [the synchronous voice tool], that's when we became most passionate about the project. We were finally were able to discuss, plan and debate issues in real time. Issues that would take 2-3 days to discuss asynchronously could be resolved in a few minutes" (synchronous voice group member).
\end{abstract}

Each of the groups concluded that asynchronous tools had their purpose, but were too slow and inefficient for spirited discussion, especially in the context of an assignment with a two-week deadline. Similarly, the synchronous tools had their strengths, but introduced scheduling problems and did not allow time for reflection and deliberation during discussion.

An important issue in distance education, and in collaborative work in particular, is social presence - the ability of learners to project themselves into a community of inquiry as real people (Rourke, Anderson, Garrison, and Archer, 1999). Looking at the reflections of this group of students, it is apparent that the learning activity - collaborative case study - was an important factor that transcended modes of communication. As social presence theorists would predict, the synchronous voice group with their instantaneous and multimodal communication tool emphasized the strength and immediacy of their group's rapport. But, so did the asynchronous voice and synchronous text groups. The following evaluations, the first from a synchronous voice student and the second from a synchronous text student, provide an interesting comparison: 
"[The group members] and I built an immediate bond. It was amazing. The sessions provided an opportunity to put a voice to the names. It added a lot to my enjoyment of the project. The voice encouragement for each other was invigorating. Another person's voice saying, 'that budget information you sent was great' really makes you feel like an important part of the group" (synchronous voice group member).

"It is interesting how individual personalities come through in this type of communication even at a distance. We typically began each session with light banter, i.e., how's the weather, how's your day going, etc. In this way, I developed a visual image of the person, became familiar with them to an extent, and also learned some basic social parameters as to what to expect from particular individuals and even boundaries. Some were more serious than others, and some you could joke with. But, having arrived at those parameters, I was then able to tailor my communication in order to work effectively with the group, and with individuals" (synchronous text group member).

Although the instructional activity seemed to have more of an effect than the communication mode, the asynchronous voice group, who switched to synchronous voice mode after the first week, did report a difference:

"We got to know each other better, faster. The [synchronous voice tool] enabled us to joke around with each other and gave us opportunity to chat about things unrelated to the task at hand. This built a community out of our team" (asynchronous voice group member).

Table 1 presents a summary of the quantitative information gathered from the students' activity-time logs. Due to the small number of participants and the interpretive nature of the study only descriptive information is provided.

Table 1. Summary of the Groups'Activity-Time Logs

\begin{tabular}{|c|c|c|c|}
\hline & Asynchronous voice & Synchronous text & Synchronous voice \\
\hline \multicolumn{4}{|l|}{ Time (hours) } \\
\hline Total & 79 & 35 & 33 \\
\hline Daily Average $^{1}$ & 5 & 2 & 2 \\
\hline \multicolumn{4}{|l|}{ Email (no,) } \\
\hline Total & 118 & 39 & 23 \\
\hline Daily Average & 7 & 3 & 1 \\
\hline \multicolumn{4}{|l|}{ Activity $^{2}$} \\
\hline Mode & 5,6 & 5,7 & 5,6 \\
\hline
\end{tabular}




\section{Notes}

${ }^{1}$ Averages represent the sum of each of the individual group member's totals, divided by the number of group members, divided by the number of days in the activity (15 days).

${ }^{2}$ Activity 5 was working towards a solution (individually), which includes consulting with experts, reading pertinent documents, conducting a literature review, and testing solution ideas (against the literature, personal experience, experts, etc.,). Activity 6 was preparing the final product (collectively), which includes developing the framework for the final product, developing a clear statement of the problem, developing a statement of the alternatives considered, developing a detailed action plan with clear documentation of the support or this plan. Activity 7 was preparing the final product (individually), which includes fulfilling individual tasks that have been assigned by the group.

The group that was assigned the asynchronous voice technology spent the most time on the project and exchanged the highest number of emails with each other. Students that were assigned the synchronous voice technology spent the least amount of time on the project and exchanged the fewest number of emails. There is little evidence, however, to suggest that the differences are attributable to the technology or that the technology was more influential than the individual personalities. Moreover, each of the groups sought and used technologies other than the one that they had been assigned. This was most dramatic in the asynchronous voice group who abandoned their technology altogether after a few days.

The logs show that the groups spent the bulk of their time engaged in two of the seven possible activities: 1) working toward a solution; and 2) preparing the final product. The former, which included activities such as reading pertinent documents, consulting with experts, conducting a literature review, and testing solution ideas, was carried out independently. The latter, which involved developing the framework for the final product, a clear statement of the problem, a statement of the alternatives considered, and a detailed action plan, was carried out both individually and collectively.

Based on the information in the students' logs, it seems more work was done independently than collaboratively. Group interviews where we asked the students how they divided their time between working individually toward the group goals and working collaboratively as a group, provided an opportunity to investigate this issue. Contrary to what the logs had shown, students felt that collaboration accounted for the bulk of their time. They confirmed that they had done much of the work individually, but noted that each decision about what to do and the evaluation of what had been done was conducted collectively.

A similar version of events emerges from the students' reflections. One student's description of her group's process recurred in many reflections:

"In the beginning, we brainstormed all our thoughts, questions, and concerns. The next phase involved working on our topics individually. Then we would get together again and ask questions to clarify assumptions or to gain further understanding of the pertinent issues. Then we went back to work, and when we were done, we all showed each other our work, looked to see where changes should be made and discussed how topics could be integrated" (synchronous text group member). 
Only one of the eleven students offered a different opinion. This member, also from the synchronous text group, seemed proud of his group's ability to spend as little time as possible meeting with each other and as much time as possible working independently:

"The group was able to distribute responsibility and assign parts of the report to members of the group and to complete the project within the deadline. I thought that in our group it was probably 70 per cent independent and 30 per cent collaborative. I think that this is a reflection of the short amount of time allowed to complete the assignment (synchronous text group member).

Though much of the work needed to be done individually, almost all of the students were anxious to work collectively with the others.

Scheduling issues were a prominent feature in many of the reflections. All of the students in the Masters of Distance Education were adults and most were working fulltime. Members of each group mentioned prior commitments, family obligations, and job responsibilities when they talked about meeting synchronously with their group. Additionally, students in this program offered by an open university were living in regions across North America. One student touched on all three scheduling issues in her reflection:

"By far, the most difficult challenge of the whole exercise was finding a mutually convenient time to meet online. The group members were from three different time zones and we all had family and work obligations. [One group member] was from Alberta and [the other two group members] were from Ontario and Florida. It took us five days before we could find a suitable meeting time. Eventually, the group settled into meeting online around 6 p.m. my time, which was an extremely inconvenient time for me as I have a two and five year old. I was unavailable during the most important times for my family - mealtime, evening time, and bedtime. I don't think we can underestimate the demands that synchronous communication can place upon working adults with family and other obligations" (synchronous text group member).

Of course, scheduling issues are not unique to distance students. However, an additional problem introduced by the Web-based communication technologies was Internet traffic. Once the groups had agreed upon a schedule that worked around all of their prior commitments and time zones, they still had to determine whether their technology would work well during that time.

The scheduling problems inherent in synchronous communication technologies were expected to be one advantage for the asynchronous technologies. However, members of the asynchronous group made comments such as:

"We found that meeting at approximately 5 p.m. MST was the most viable option because of the three-hour time zone difference amongst our group." And "It was very time consuming to refresh the browser, expand each of the message threads, record a new message, and then repeat the process" (asynchronous voice group members). 
The reason users of the asynchronous system were concerned about finding a good meeting time and refreshing their browsers is because their strategy was to be online simultaneously and attempt to communicate with each other synchronously. One member explained: "Our group tried to use the asynchronous voice technology as a synchronous communications tool when we needed to brainstorm solutions, have discussions, and distribute the tasks” (asynchronous group member). Thus, the scheduling problems were not restricted to synchronous technologies.

When students mentioned learning in their reflections, they referred to things such as learning how to use the software and learning how to work in groups, but the comments that were most interesting were their references to learning the course content.

Three issues were prominent in their descriptions of learning the course content. First, students said that they gained the most knowledge about the particular section of the case that they were working on. This may not seem surprising; however, put another way, one could say that some of students were able to come away with surprisingly little knowledge about other parts of the case. One of the synchronous voice students, for instance, reported:

"My own learning was greatest in the areas in which I was 'person most responsible' and involved consulting the course textbook, study guide readings, and researching online."

A synchronous text group member recounted a similar experience, and distinguishes it from learning about the other group members' foci:

"Conducting the readings and doing the research on my topic was a good opportunity to learn a lot about [that topic]. I expected to learn a lot about [the others' topics], but there was only enough time for me to get a superficial understanding of their issues and how they affected my part of the report."

Students attribute a large part of their learning, particularly the higher order learning, to collaboration with their group members. Some of the higher order processes students described included self-reflection, knowledge application, decision-making, and criticism and revision of concepts and solutions. A student in the synchronous voice group described the process:

"At the outset it seemed that there was some disagreement on some of the key issues. As the issues were discussed and personal experiences were shared, the group seemed to integrate each other's thinking and move toward a consensus. Brainstorming was used to help our group solve the problem as a number of suggestions were narrowed down to the most appropriate choice. The sharing of ideas seemed to make all of the members more aware of the complexities of the issue."

These types of processes were found across groups and communication systems.

An important element in learning for these students was the motivation prompted by the group work. For some, this came as a surprise because of negative experiences they had in the past. For example, one student in the asynchronous voice group asked: 
"I went into the project expecting the usual. That is, I'd work myself to the bone while my partners talked about philosophical or personal issues that had little to do with completing the task at hand. Why would I put myself in such a position?”

Nonetheless, by the time the students wrote their reflections, this attitude had changed. The same student, fifteen days later wrote:

"If all my future collaborative projects are like this one, I cannot wait for my next group project! Connecting with my group-mates energized and invigorated me."

Aside from the general enthusiasm and satisfaction attributable to the group work, it also prompted some of the students to work harder. "To know that there would be questions to answer, and not wanting to be guilty of non-performance, drove me to have my work in ready-plus mode” said one student. Another student from a different group expanded on the idea:

"As I wanted to contribute to the group discussion in a meaningful way, I believe I was more motivated to read and digest the course materials in anticipation of the group work. I had previewed all of the course materials and had read extensively about [the topic] before the commencement of the project (synchronous text group member).

\section{Discussion}

The purpose of this investigation was to explore the relative capacity of various Webbased, group communication systems to support case-based teaching at a distance. Learning achievement and satisfaction levels among this group of students indicate that the systems were effective in supporting this method of learning. But the question remained: Which communication system was most effective at supporting this learning activity? Participants showed us that case-based learning involves several activities, and they judiciously selected appropriate media for each activity. Asynchronous technologies, such as email, were useful for arranging meetings and sharing provisional documents, while synchronous technologies were more useful for brainstorming and decisionmaking. Daft and Lengel's (1984) media richness theory, which argues that media are differentially suited to different tasks, is most consonant with these findings.

Unfortunately, the design of our study did not enable us to attribute many of the interesting outcomes to a particular communication system. Students' activity-time logs, for instance, indicate that the asynchronous group took twice as long as the synchronous groups to complete the assignment. However, it is not clear whether this is a function of the communication mode, the group personalities, or some other factor. Subsequent researchers may design studies that will allow them to probe questions such as these more decisively.

Nonetheless, this exploratory study does yield some implications for instructional designers who wish to exploit the power of the case study method in a distance education context. Based on the results of this study and the work of communication theorists (cf. Daft and Lengel, 1984; Short et al., 1976), it seems convincing that media are differentially suited to various tasks. Therefore, the more modes of communication to which the students have access, the more likely they are to have successful and satisfying 
interactions with their group members. Our attempt to limit the groups to one communication technology prompted them to first, attempt to use asynchronous technologies in the synchronous mode and, second, to abandon their assigned technology in favour of others they thought would be more useful.

Instructors should also note that some of the students commented that they learned the most about the section of the case study on which they worked. In this case study, for example, it was common for groups to divide the case into three sections - budgeting, learning management systems, and change issues - and then assign one section to each member. Students then developed a thorough understanding of their section, but could remain disappointingly uninformed about the other topics. Any other assumptions about students' learning may be inaccurate.

\section{References}

Armitt, G., Slack, F., Green, S., and Beer, M. (2002). The development of deep learning during a synchronous collaborative online course. Paper presented at Computer Supported Collaborative Learning '02. Boulder. Co.: University of Colorado. Retrieved Aug. 1, 2002 from: http://www.newmedia.colorado.edu/cscl/70.pdf

Clark, R. E. (1994). Media will never influence learning. Educational Technology Research and Development, 42(2), 21 - 29.

Borsa, J., Klotz, J., and Uzat, R. (1998). Utilizing distance learning and the case study method to enhance instruction between two universities. ERIC: ED 429270.

Cheney, C. (2000). Combining distance education and Web applications for a course on collaboration in special education. ERIC: ED 439889.

Clark, R. E. (1994). Media will never influence learning. Educational Technology Research and Development 42(2), pp. 21 - 29.

Educational Resources Information Center (2002). “Case method,” Scope note for.

Hunter, W. (1997). Case-based teaching workshop. Retrieved, May 3, 2002 from: http://www.fp.ucalgary.ca/hunter/

Kemmis, S., and McTaggart, R. (1988). The action research reader (3rd ed.). Victoria: Deakin University Press.

Lundeberg, M., Levin, B., and Harrington, H. (1999). Who learns what from cases and how? The research base for teaching and learning with cases. Mahwah, NJ.: Lawrence Erlbaum Associates.

Lundeberg, M. (1999). Discovering teaching and learning through cases. In M. Lundeberg, B. Levin, and H. Harrington (Eds.) Who learns what from cases and how? The research base for teaching and learning with cases (p. 3-23). New Jersey: Lawrence Erlbaum Associates.

Roby, T. W. (1988). Models of discussion. In J. Dillon (Ed.) Questioning and Discussion: A multidisciplinary study (p.163-191). Norwood, NJ.: Ablex. 
Rourke, L., Anderson, T. Garrison, D. R., and Archer, W. (1999). Assessing social presence in asynchronous, text-based computer conferencing. Journal of Distance Education, 14(3), 51 - 70.

\section{Acknowledgements}

The authors wish to thank the developers of TutorsEdge (www.eluminate.com), Wimba (www.wimba.com) and MSN Messenger *www.messenger.msn.com) for the free use of their software products for this project.

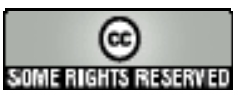

